American J. of Engineering and Applied Sciences 2 (1):147-153, 2009

ISSN 1941-7020

(C) 2009 Science Publications

\title{
The Performance of Uncoated Tungsten Carbide Insert in End Milling Titanium Alloy Ti-6Al 4V through Work Piece Preheating
}

\author{
L. Turnad Ginta, Mohd Amri Lajis and A.K.M. Nurul Amin \\ Faculty of Engineering, International Islamic University, 86400 Kuala Lumpur, Malaysia
}

\begin{abstract}
Problem statement: Titanium alloys have been used widely in the aerospace, chemical and petroleum industry because of their high specific strength, fracture resistance and superior resistance to corrosion. Titanium alloys have a very high strength-to-weight ratio making them very suitable for aircraft engines and airframe manufacture. Approach: The use of titanium alloys as engine component materials is due to their ability to maintain their high strength at high operating temperatures of the engine. Titanium alloys exhibit exceptional resistance to corrosion, which provides savings on protective coating like paints that will otherwise be used in the case of steel. However, titanium alloys are difficult to machine due to their high temperature strength, low modulus of elasticity, low thermal conductivity and high chemical reactivity. Results: This study presented the investigation of tool life improvement in end-milling of Titanium Alloy Ti-6Al-4V through workpiece preheating. End milling tests were conducted on Vertical Machining Centre with full immersion cutting. Titanium alloy Ti$6 \mathrm{Al}-4 \mathrm{~V}$ bar was used as the workpiece. Machining was performed with a $20 \mathrm{~mm}$ diameter end-mill tool holder fitted with one uncoated WC-Co carbide inserts. All of the experiments were run under room temperature and preheating condition at 315,450 and $650^{\circ} \mathrm{C}$. Induction heating was utilized during end milling with preheating. Flank wear has been considered as the criterion for tool failure and the wear was measured using a Hisomet II Toolmaker's microscope. Tests were conducted until an insert rejected when an average flank wear greater than $0.30 \mathrm{~mm}$ was recorded. Cutting force and torque measurements were conducted using the Kistler Rotating Cutting Force Dynamometer. Vibration during cutting was captured using an online vibration monitoring system. Scanning Electron Microscope (SEM) was also used to investigate the wear morphology. Conclusion/Recommendation: The results lead to conclusions that workpiece preheating significantly increases the tool life of uncoated WC-Co carbide inserts in end-milling of Titanium Alloy Ti-6Al-4V. An increase in tool life by $325 \%$ was achieved while employing preheating at $650^{\circ} \mathrm{C}$ compared to the experiment at room temperature.
\end{abstract}

Key words: Workpiece preheating, titanium alloy Ti-6Al-4V, tool life, surface alteration

\section{INTRODUCTION}

Titanium alloys are widely used in the turbine industry due to their superior mechanical, chemical and high temperature properties. Titanium alloys are generally used for structural applications, such as cases and impellers. For these alloys, machining productivity is limited by tool wear which indirectly represents a significant portion of the machining costs as such they are known as difficult-to-cut materials. However, by properly selecting the tool material and cutting conditions an acceptable rate of tool wear may be achieved and thus lowering the total machining $\operatorname{cost}^{[1]}$. The performance of a cutting tool is normally assessed in terms of its life. Wear criteria are usually used in assessing tool life. Mostly, flank wear is considered, since it largely affects the stability of the cutting wedge and consequently the dimensional tolerance of the machined work surface ${ }^{[2]}$.

Machining of titanium alloys was the subject of interest for many years. Ginta et $a l^{[3]}$ developed the surface roughness models in end milling Ti-6Al-4V using uncoated WC-Co and PCD inserts. They found that feed has the most significant influence on surface roughness, followed by cutting speed and axial depth of cut. Jawaid et al $^{[4]}$ studied the tool wear characteristic in turning titanium alloy Ti-6246. They found that inserts with fine grain size and a honed edge have a

Corresponding Author: Turnad L. Ginta, International Islamic University Malaysia, P.O. Box 10, 50728 Kuala Lumpur, Malaysia 
longer tool life. At higher cutting speeds the tool failure was due to maximum flank face wear and excessive chipping on the flank edge. Ribeiro et al. ${ }^{[5]}$ studied the optimization aspect of titanium alloy Ti-6Al-4V machining. They suggested that the best cutting conditions were close to the suitable conditions for the tool manufacturer. However, it is possible to work in more severe conditions than the manufacturer's conservative conditions.

The use of workpiece preheating (hot machining) as a technique for improving machining operations has been under consideration since the late 19th century. This was informed by understanding that metals tend to deform more easily when heated, thus enhancing machining. The principle behind hot machining is increasing difference in hardness of the cutting tool and workpiece, leading to reduction in the component forces, improved surface finish and longer tool life ${ }^{[6]}$. Amin and Talantov ${ }^{[7]}$ studied the influence of the furnace method of preheating of workpiece on machinability of titanium alloy BT6 (Russian Standard) and found that all the vertical cutting force component decreases with the increase in the preheating temperature but the radial and the axial components sharply increase to their peak values at a particular temperature. This temperature was termed as the optimum preheating temperature for the investigated titanium alloy. It was observed that the length of chiptool contact was very small $(0.5 \mathrm{~mm})$ compared to that of steels during room temperature machining, but under preheated condition the length of contact increased to $1.0 \mathrm{~mm}$ at the optimum temperature. The tool wear rate was also found to be the minimum at this temperature. Expected tool life for an average flank wear of $0.3 \mathrm{~mm}$ was calculated for the optimum preheating temperature from the slope of the corresponding curve and was found to be about $3000 \mathrm{sec}$ against $160 \mathrm{sec}$ at room temperature.

Ozler et al. ${ }^{[8]}$ carried out hot-machining operation using austenitic manganese steel as work-piece material using gas flame heating. Leshock et al. ${ }^{[9]}$ used numerical and experimental analysis of Plasma Enhanced Machining (PEM) of Inconel 718. They evaluated that peak temperatures must be known so that thermal damage is prevented or minimized in the workpiece surface. They also found that the ability to predict the temperature distribution is the first step in optimizing thermally enhanced machining.

The main objective of this study is to investigate the effect of workpiece preheating with high frequency induction heating on improvement of tool life of uncoated WC-Co inserts during end milling Ti-6Al-4V.
Tool wear, vibration, cutting force and surface integrity were also investigated during the experiments.

\section{MATERIALS AND METHODS}

Workpiece material: The workpiece material used in all experiments was alpha-beta titanium alloy $\mathrm{Ti}$ $6 \mathrm{Al} 1 \mathrm{~V}$. The microstructure of this workpiece is shown in Fig. 1. The microstructure consists of both coaxial and columnar alpha phase and inter-granular beta phase. The composition of the alloys (in wt\%) is shown in Table 1 and the mechanical properties in Table 2.

Cutting tool material: Sandvick uncoated tungsten carbide inserts were used in the experiments. One insert has two cutting edges. The inserts profile and geometry data are shown in Table 3.

Table 1: The composition of Titanium Alloy Ti-6Al-4V

\begin{tabular}{llllll}
\hline \multicolumn{7}{l}{ Chemical composition (wt.\%) } \\
\hline $\mathrm{Al}$ & $\mathrm{V}$ & $\mathrm{C}_{(\max )}$ & $\mathrm{Fe}_{(\max )}$ & $\mathrm{N}_{2(\max )}$ & $\mathrm{O}_{2(\max )}$ \\
\hline $5.5-6.76$ & $3.5-4.5$ & 0.08 & 0.25 & 0.05 & 0.2 \\
\hline
\end{tabular}

Table 2: The mechanical properties of Titanium Alloy Ti-6Al-4V

\begin{tabular}{llll}
\hline $\begin{array}{l}\text { Ultimate tensile } \\
\text { strength }(\mathrm{MPa})\end{array}$ & $\begin{array}{l}\text { Elongation } \\
(\%)\end{array}$ & $\begin{array}{l}\text { Elastic modulus } \\
(\mathrm{GPa})\end{array}$ & $\begin{array}{l}\text { Hardness } \\
(\mathrm{HV} 0.5)\end{array}$ \\
\hline 897 & 10 & 114 & 320 \\
\hline
\end{tabular}

Table 3: Cutting tool material and geometry data

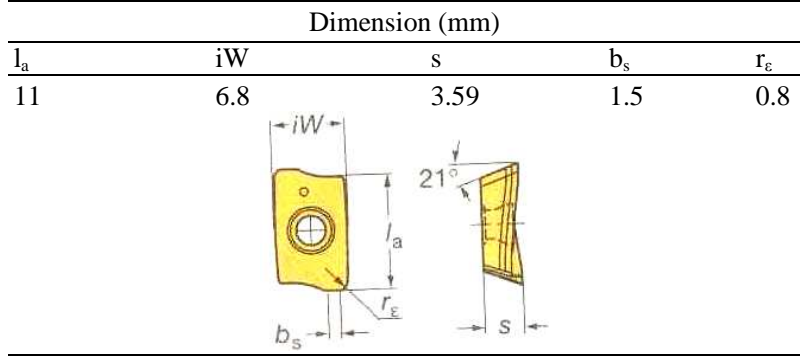

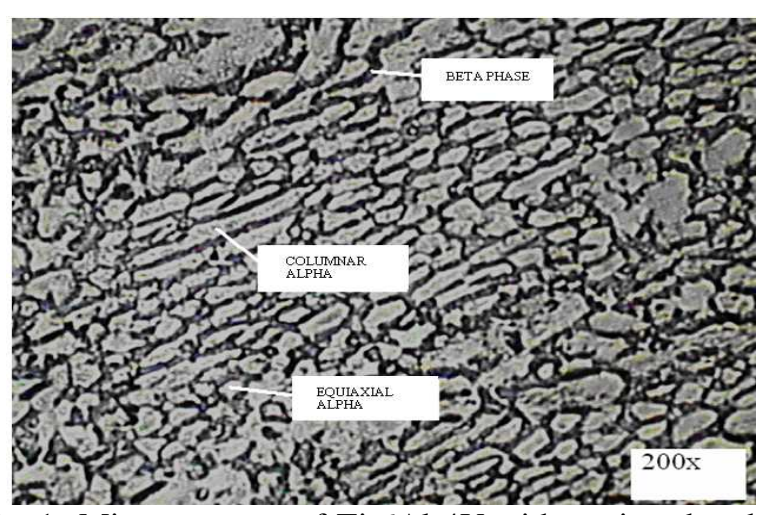

Fig. 1: Microstructure of Ti-6Al-4V with equiaxed and columnar alpha grains (light) with intergranular beta phase (dark); Etchant: $10 \% \mathrm{HF}, 5 \% \mathrm{HNO}_{3}$, $85 \% \mathrm{H}_{2} \mathrm{O}$ 
Experimental works: End milling tests were conducted on Vertical Machining Centre (VMC ZPS, Model: MLR 542 with full immersion cutting. Titanium alloy Ti-6Al-4V bar was used as the work-piece. Machining was performed with a $20 \mathrm{~mm}$ diameter endmill tool holder (R390-020B20-11M) fitted with one insert. Uncoated tungsten carbide inserts (R390-11T3 08E-NL-H13A) were used in the experiments. All of the experiments were run at room temperature and with preheating. High frequency induction heating was utilized to run the preheated machining. Selected cutting conditions for the experimentation are shown in Table 4.

The experimental set up for the machining is shown in Fig. 2. Depending on the cutting conditions and wear rate, machining was stopped at various interval of cutting length from $100-200 \mathrm{~mm}$ to record the wear of the inserts. Flank wear has been considered as the criteria for tool failure and the wear was measured under a Hisomet II Toolmaker's microscope. Testing under room temperature condition was stopped when an average flank wear achieved exceeded $0.3 \mathrm{~mm}$. Scanning Electron Microscope (SEM) was employed to investigate tool wear and tool morphology. Linear regression was used to find the tool life value for experiment with preheating at $650^{\circ} \mathrm{C}$ (because the experiment was stopped when the flank wear reached $0.15 \mathrm{~mm}$ ) in view of high tool life. Cutting force and torque measurements were conducted using the Kistler Rotating Cutting Force Dynamometer. Workpiece samples for subsurface analysis were cut using Electrical Discharge Wire Machine (EDWM). These samples were then mounted using hot mounting,

Table 4: Cutting condition for experimental work

\begin{tabular}{|c|c|}
\hline Cutting parameters & Values \\
\hline Cutting speed $\left(\mathrm{m} \mathrm{min}^{-1}\right)$ & 70 \\
\hline Feed $\left(\mathrm{mm}\right.$ tooth $\left.^{-1}\right)$ & 0.088 \\
\hline Axial depth of cut (mm) & 1 \\
\hline Radial depth of cut (mm) & 20 (full immersion) \\
\hline Preheating temperature $\left({ }^{\circ} \mathrm{C}\right)$ & Room temperature, $315,450,650$ \\
\hline
\end{tabular}

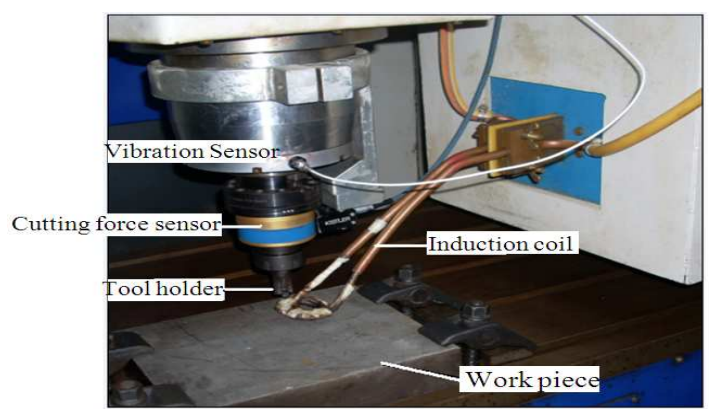

Fig. 2: Experimental set-up ground using silicon carbide paper, polished with an alumina solution and then etched with $10 \% \mathrm{HF}, 5 \%$ $\mathrm{HNO}_{3}$ and $85 \% \mathrm{H}_{2} \mathrm{O}$ prior to inspection. An optical microscope connected to a CCD camera with a micro hardness unit employing a Vickers indenter, was employed in the micro hardness measurements. Hardness measurements were made using $50 \mathrm{~g}$ load.

\section{RESULTS}

Tool life: Figure 3 shows progression of the typical flank wear of uncoated tungsten carbide inserts in end milling Ti-6Al-4V at room temperature and with preheating $\left(315,450\right.$ and $\left.650^{\circ} \mathrm{C}\right)$. It appears that tool life was significantly influenced by preheating. Experiment at room temperature gives $17.1 \mathrm{~min}$ in tool life, but experiment with preheating gives an improvement of tool life by 1.1, 1.4 and 3.25 times at preheating temperature of 315,450 and 650 , respectively, compared to that in experiment at room temperature. Workpiece preheating at $650^{\circ} \mathrm{C}$ gives the longest cutting time $(55.7 \mathrm{~min})$ before achieving $0.3 \mathrm{~mm}$ of flank wear compared to the experiment at room temperature (17.1 $\mathrm{min}$ ) as shown in Fig. 4.

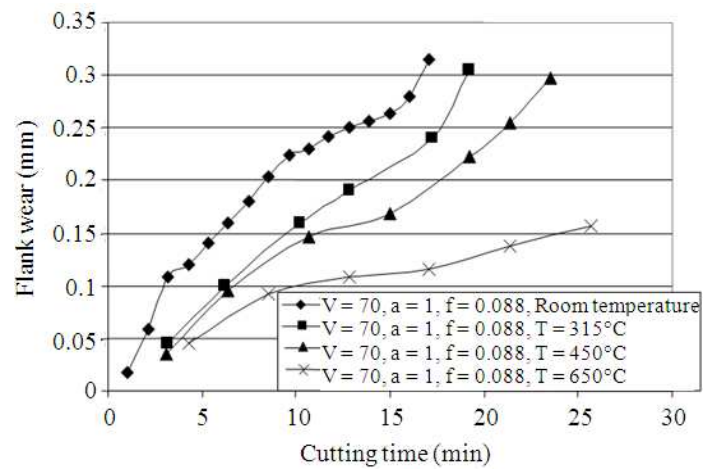

Fig. 3: Average flank wear of uncoated WC-Co at different preheating temperature

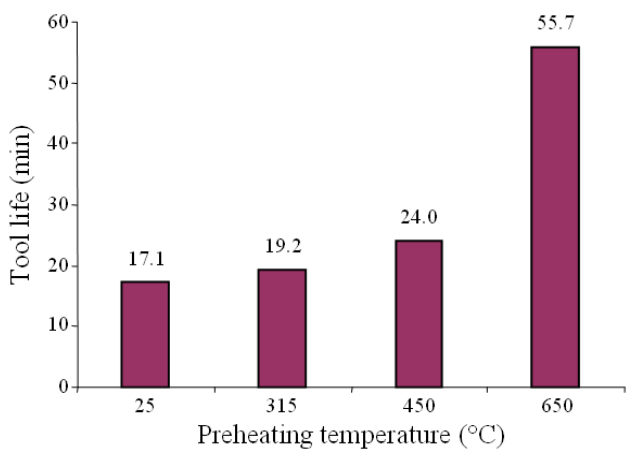

Fig. 4: Tool life vs preheating temperature 


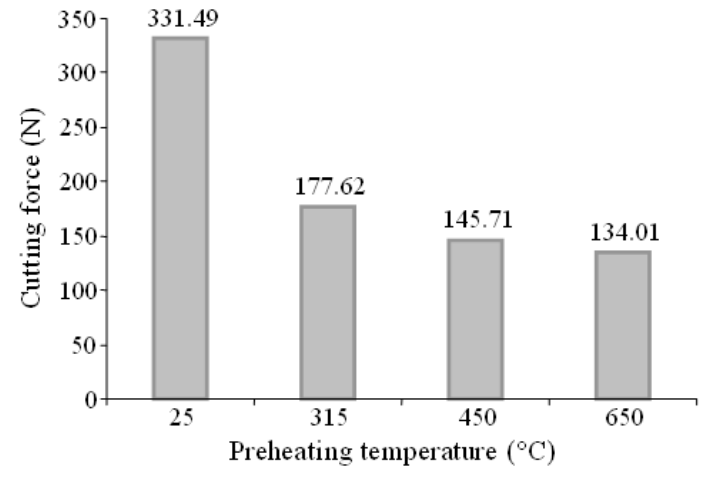

Fig. 5: Cutting force Vs preheating temperature
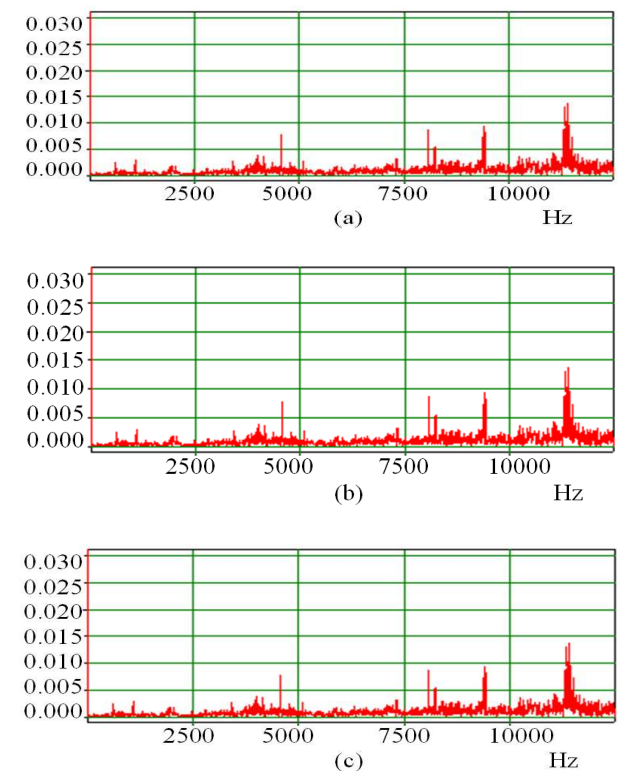

Fig. 6: FFT output of end milling Ti-6Al-4V (cutting speed $70 \mathrm{~m} \mathrm{~min}^{-1}$, axial depth of cut $1 \mathrm{~mm}$, feed $0.088 \mathrm{~mm}$ tooth $^{-1}$ ) at: (a): Room temperature, (b): $450^{\circ} \mathrm{C},(\mathrm{c}): 650^{\circ} \mathrm{C}$

Table 5: Acceleration amplitudes of vibration and the percent reduction

\begin{tabular}{|c|c|c|c|c|c|}
\hline \multirow[b]{2}{*}{$\begin{array}{l}\text { Frequency } \\
\text { range }(\mathrm{Hz})\end{array}$} & \multicolumn{5}{|c|}{ Maximum acceleration amplitude $(\mathrm{mV})$} \\
\hline & $\begin{array}{l}\text { Room } \\
\text { temperature }\end{array}$ & $450^{\circ} \mathrm{C}$ & $\begin{array}{l}\text { Reduction } \\
(\%)\end{array}$ & $650^{\circ} \mathrm{C}$ & $\begin{array}{l}\text { Reduction } \\
(\%)\end{array}$ \\
\hline $2,500-5,000$ & 0.007 & 0.006 & 14.3 & 0.004 & 42.9 \\
\hline $7,500-10,000$ & 0.009 & 0.007 & 22.2 & 0.005 & 44.4 \\
\hline $10,000-12,500$ & 0.013 & 0.008 & 38.4 & 0.004 & 69.2 \\
\hline
\end{tabular}

Figure 6 shows the effect of preheating in reducing the amplitude of vibration during machining. Figure 6a represents the FFT outputs for room temperature machining and Fig. $6 \mathrm{~b}$ and $\mathrm{c}$ for preheated machining at 450 and $650^{\circ} \mathrm{C}$, respectively.
Tool wear morphology: Figure 7 shows the SEM micrograph of flank wear after end milling at room temperature and with preheating experiments. End milling at room temperature condition caused severe tool wear with catastrophic morphology as shown in Fig. 7a. Tool wear was also found to be uniform in the case of preheated machining. It appears that preheating has effects on reducing the wear. Figure 7a shows the SEM views of flank wear of cutting tool after machining titanium alloys Ti-6Al-4V at room temperature during $17.1 \mathrm{~min}$ and Fig. $7 \mathrm{~d}$ shows the flank wear of cutting tool after machining with preheating at $650^{\circ} \mathrm{C}$ during $26.5 \mathrm{~min}$. Two pictures reflect that preheating could significantly reduce the too wear, hence, leads to increasing in tool life.

Built Up Edge (BUE) occurs in room temperature as well as in preheated conditions as shown in Fig. 8. High chemical reactivity of titanium alloys leads to BUE. An increase in preheating temperature, leads to an increase in chemical reactivity between chips or tool materials and cutting tools and which leads to the formation of BUE. Figure 8a and b show the evidence of BUE under room temperature and preheated machining conditions, respectively.

It is affirmed from above analysis that preheating leads to a reduction in amplitude of vibration and cutting force during cutting. Lower vibration and cutting force will reduce the dynamic loads on the edge which leads to lower tool wear. Softer workpiece reduces the stress acting on the tool and it has responsible for reducing tool wear and increasing the tool life.

Subsurface alteration: Figure 9 shows the distribution of micro hardness of the subsurface after cutting at room temperature and with preheating. The measurements were taken at a length interval $0.01 \mathrm{~mm}$ starting from the top surface up to a depth of $0.5 \mathrm{~mm}$ beneath the surface. According to the hardness, the surface layer is divided into three zones, heat affected zone (Zone 1), strain hardened (Zone 2) and base material (Zone 3).

The averages of micro hardness in Zone 1 are relatively lower than that of the base materials (Zone 3). The heat which is generated during cutting has effects in softening the thin layer below the surface. This heat is quite sufficient as a driving force to promote annealing arrangements within the microstructures. The higher preheating temperature, leads to lower hardness distribution beneath the surface. This is related to the higher temperature that are induced when employing preheating. Heat affected zone was recorded up to a depth of $\sim 150 \mu \mathrm{m}$. 


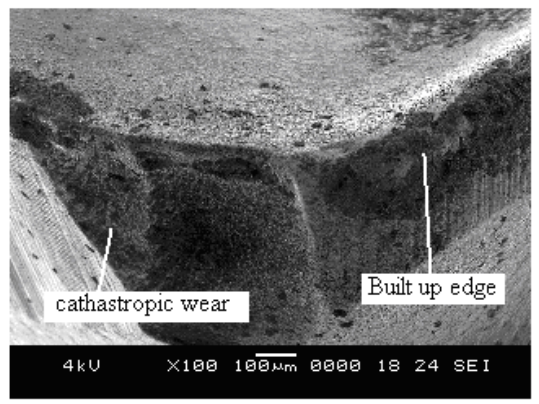

(a)

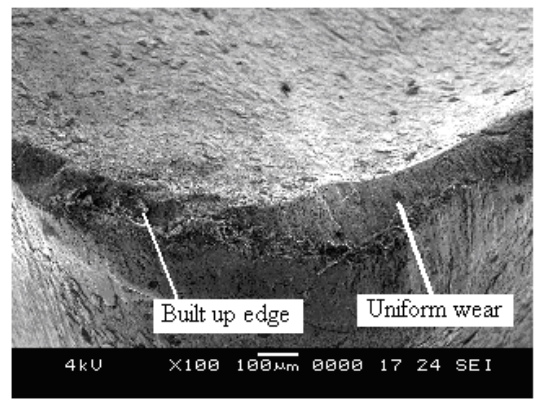

(c)

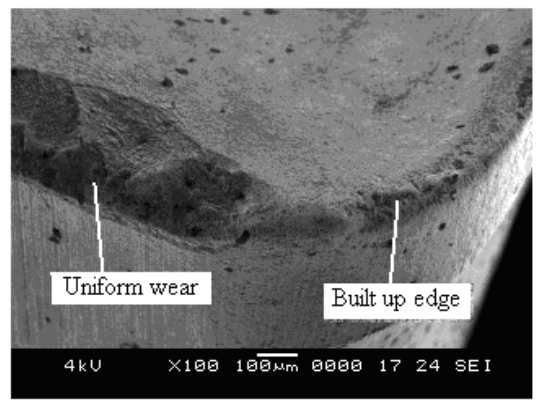

(b)

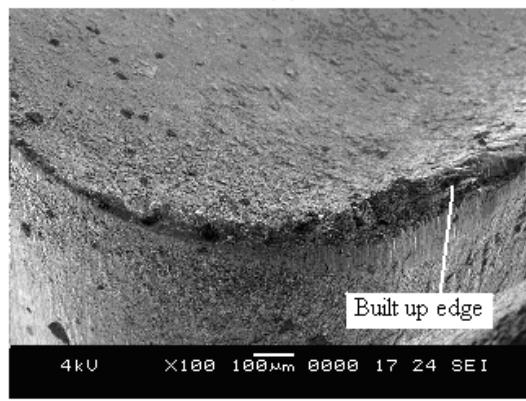

(d)

Fig. 7: SEM views of flank wear: (a): At room temperature after 17.1 min cutting, (b): With preheating at $315^{\circ} \mathrm{C}$ after 19.2 min cutting, (c): With preheating at $450^{\circ} \mathrm{C}$ after 24 min cutting and (d): With preheating at $650^{\circ} \mathrm{C}$ after 26.5 min cutting. (All experiments run at cutting speed $70.1 \mathrm{~m} \mathrm{~min}^{-1}$, axial depth of cut $1 \mathrm{~mm}$ and radial depth of cut $20 \mathrm{~mm}$ )

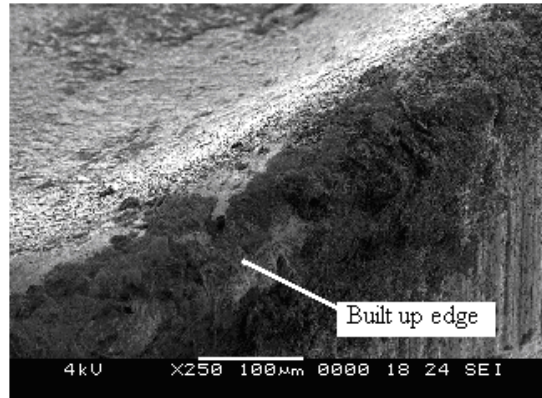

(a)

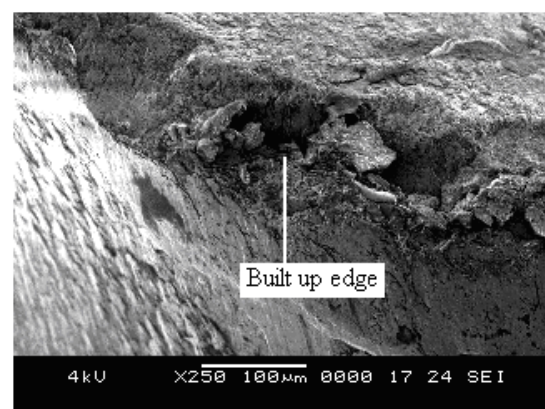

(b)

Fig. 8: SEM views of built up edge: (a): At room temperature, (b): With preheating at $650^{\circ} \mathrm{C}$

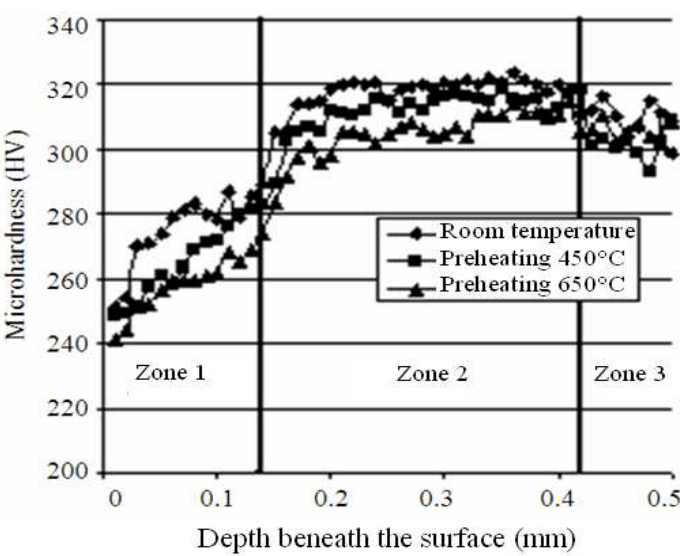

Fig. 9: Microhardness value beneath the machined surface

Extensive strain hardening has occurred during machining, especially during room temperature cutting. Plastic deformation which is generated during cutting initiates dislocation movements and induces strain hardening. Strain hardening zone was noticed to a depth of $\sim 400 \mu \mathrm{m}$. In case of preheating, the heat which is resulted from preheating acts to withstand the dislocation multiplications and reduce the effects of 
strain hardening by giving driving force to atomic dislocation movements. As a result, strain hardening does not occur.

\section{DISCUSSION}

Most appreciable improvement of tool life takes place with an increase of preheating temperature. This is related to the lowering of cutting force with preheating temperature (Fig. 5) and suppression of chatter during preheated machining. The results show that preheating reduces the cutting force from $331.5 \mathrm{~N}$ at room temperature to $134 \mathrm{~N}$ with preheating at $650^{\circ} \mathrm{C}$. This reduction related to the workpiece softening caused by the preheating. An increase of preheating temperature gives a reduction in cutting force.

An analysis of the vibration output is shown in Table 5. It may be observed from Fig. 6 that there are three main peaks in the range of 2,500-12,500 Hz. The most significant peaks during room temperature cutting are at $4510 \mathrm{~Hz}$ with amplitude value of $0.007,9450 \mathrm{~Hz}$ with amplitude value of $0.009 \mathrm{mV}$ and are at $11,500 \mathrm{~Hz}$ with the amplitude value of $0.013 \mathrm{mV}$. Reduction in amplitude values varies from $14.3-38.4 \%$ and from 42.9-69.2\% in experiments with preheating temperature at 450 and $650^{\circ} \mathrm{C}$, respectively.

It is affirmed from above analysis that preheating leads to a reduction in amplitude of vibration and cutting force during cutting. Lower vibration and cutting force will reduce the dynamic loads on the edge which leads to lower tool wear. Softer workpiece reduces the stress acting on the tool and it has responsible for reducing tool wear and increasing the tool life.

\section{CONCLUSION}

The following specific conclusions have been drawn on the work:

- Preheating helps in substantially increasing tool life during end milling Ti-6Al-4V using uncoated tungsten carbide inserts. Experiment with preheating at $650^{\circ} \mathrm{C}$ gives benefit in increasing tool life by 3.25 times compared to the experiment at room temperature. High frequency induction heating was proved as a suitable technique for preheated machining

- Preheating helps in appreciable lowering down the cutting force values during cutting and reducing acceleration amplitude of vibration. Experiment with preheating at $650^{\circ} \mathrm{C}$ can significantly reduce the magnitude of cutting force and acceleration amplitude of vibration 60 and $70 \%$, respectively
- Built up edge is a big problem in cutting Titanium Alloy Ti-6Al-4V. Evidence of built up edge was found in both room temperature and preheating experiments. This is related to the high chemical reactivity between workpiece material and the cutting tools

- Cutting titanium alloys significantly generate high temperature, which leads to softening or annealing effects to the depth of $\sim 150 \mu \mathrm{m}$. Extensive strain hardening has also occurred during machining, especially at room temperature cutting. Workpiece preheating could substantially reduce the effect of strain hardening

\section{AKNOWLEDGEMENT}

The researchers wish to thank Ministry of Science, Technology and Innovation (MOSTI) Malaysia for their financial support to the above project through the eScience Fund Project (Project No.03-01-08-SF0001). And the research management centre IIUM for overall management of the project.

\section{REFERENCES}

1. Kishawya, H.A., C.E. Becze and D.G. McIntosh, 2004. Tool performance and attainable surface quality during the machining of aerospace alloys using self-propelled rotary tools. J. Mater. Process. Technol., 152: 266-271. DOI: 10.1016/j.jmatprotec.2003.11.011

2. Turnad, L., A.K.M. Ginta, Nurul A.N.M. Amin, Karim and A.G. Sutjipto, 2007. Tool life prediction by response surface methodology for end milling titanium alloy $\mathrm{Ti}-6 \mathrm{Al}-4 \mathrm{~V}$ using uncoated carbide inserts. Proceeding of the International Conference on Mechanical Engineering, Dec. 29-31, ICME, Dhaka, Bangladesh.

3. Ginta, T.L., A.K.M. Nurul Amin, A.N.M. Karim and M.H. Ishtiyaq, 2007. Modelling for surface roughness in end-milling of titanium alloy ti-6AL$4 \mathrm{~V}$ using uncoated WC-CO and PCD inserts. Proceeding of the 4th International Conference on Leading Edge Manufacturing in the 21st Century, Nov. 7-9, Fukuoka, Japan, pp: 23-28.

4. Jawaid, A., C.H. Che-Haron and A. Abdullah, 1999. Tool wear characteristics in turning of titanium alloy Ti-6246. J. Mater. Process. Technol., 92-93: 329-334. DOI: 10.1016/S09240136(99)00246-0

5. Ribeiro, M.V., M.R.V. Moreira and J.R. Ferreira, 2003. Optimization of titanium alloy (6Al-4V) machining. J. Mater. Process. Technol., 143-144: 458-463. DOI: 10.1016/S0924-0136(03)00457-6 
6. Krabacher, E.J. and M.E. Merchant, 1951. Basic factors in hot machining of metals. Trans. ASME., 73: 761-776.

7. Amin, A.K.M.N. and N.V. Talantov, 1986. Influence of the instability of chip formation and preheating of work on tool life in machining high temperature resistance steel and titanium alloy. Mech. Eng. Res. Bull., 9: 52-62.

8. Ozler, L., A. Inan and C. Ozel, 2001. Theoretical and experimental determination of tool life in hot machining of austenitic manganese steel. Int. J. Mach. Tool Manufact., 41: 163-172. DOI: 10.1016/S0890-6955(00)00077-8
9. Leshock, C.E., J.N. Kim and C.Y. Shin, 2001. Plasma enhanced machining of Inconel 718: Modelling of workpiece temperature with plasma heating and experimental results. Int. J. Mach. Tools Manufact., 41: 877-897. DOI: 10.1016/S0890-6955(00)00106-1 